\title{
Ice loss in the Northeastern Tibetan Plateau permafrost as seen by 16 years of ESA SAR missions
}

\author{
Simon Daout ${ }^{1}$, Benedetta Dini ${ }^{2}$, Wilfried Haeberli ${ }^{3}$, Marie-Pierre Doin ${ }^{4}$, \\ Barry Parsons ${ }^{1}$
}

\begin{abstract}
InSAR time series of surface deformation from 16 years of Envisat (2003-2011) and Sentinel-1 (2014-2019) ESA satellite radar measurements have been constructed to characterise spatial and temporal dynamics of ground deformation over an $80,000 \mathrm{~km}^{2}$ area, in the permafrost of the northeastern Tibetan Plateau. The regional deformation maps encompass various types of periglacial landforms and show that seasonal thaw effects are controlled by the sediment type and local topography. High seasonal ground movements are concentrated on shallow slopes and poor-drainage areas in unconsolidated, frost-susceptible and finegrained sediments within glacier outwash plains, braided stream plains, alluvial deposits or floodplains. Fast subsidence due to thaw settlement takes place during June/July while frost heave is intense during December/January when two-sided freezing of pore water under pressure causes prolonged ice segregation near the permafrost table. The analysis reveals pervasive subsidence of the ground of up to $\sim 2 \mathrm{~cm} / \mathrm{yr}$, and increasing by a factor of 2 to 5 from 2003 to today, in high-relief and well-drained areas. The findings suggest that seasonal thaw increasingly affects ice-rich layers at the permafrost table, as well as highrates of widespread mass movements of non-consolidated sediments, the latter amplified by an increase of effects from frost heave/thaw settlement.
\end{abstract}

\footnotetext{
${ }^{1}$ COMET, Department of Earth Sciences, University of Oxford, UK

${ }^{2}$ School of Environmental Sciences, University of East Anglia, UK

${ }^{3}$ Department of Geography, University of Zurich, Switzerland

${ }^{4}$ Univ. Grenoble Alpes, Univ. Savoie Mont Blanc, CNRS, IRD, IFSTTAR, ISTerre, 38000 Grenoble, France
} 
Keywords: Permafrost degradation, Freeze/thaw cycles, solifluction, InSAR time series, Northeast Tibet.

1

5

\section{Introduction}

Tibet is not simply a flat and elevated plateau but alternates mountain ranges with wide internally-drained plains, where tectonic activity, erosion, and sedimentation are interacting to reshape the Earth's surface [1, 2]. Above $\sim 3500 \mathrm{~m}$-height, where the mean ground surface temperature is below $0^{\circ}$, permafrost is present in the ground [e.g., 3, 4, 5] and excess ice in frost-susceptible materials of the active layer thaws during summer and fall months and heaves in winter to spring months, resulting in cyclic surface movements [e.g 6]. Evidence of frost-related processes is widespread in the Tibetan landscape but varies depending on the relief [1]. On slopes, water is drained and the cover of allochthonous material is reworked by mass wasting processes such as those driven by glacial/fluvial activity, deep-seated creep of frozen materials, solifluction, or debris flows. On lowlands and undrained regions, polygonal cracks, thermokarst lakes and ice-cored mounds attest to the ice-rich layers near the permafrost table.

Recent studies, mainly at local scales of a few $\mathrm{km}^{2}$, have highlighted the potential of multitemporal radar interferometry (MT-InSAR) to detect and monitor the seasonal ground displacements attributed to the freeze and thaw cycles of the water stored in the shallow layers of the ground [e.g., 7, 8, 9, 10, 11, 12, 13. The recent launch of Sentinel-1 satellites with systematic acquisitions in ascending and descending orbits and with a shorter revisit time (down to 6 days) allows scientists to investigate in much more detail the seasonal and inter-annual deformation response of the frozen ground to climate forcing at regional scale.

The impacts that permafrost has on engineering constructions, infrastructure stability (e.g. along the Qinghai-Tibet Plateau Engineering Corridor [e.g., 14,

15, 16, 17, 18, 19]) and on gravitational processes that can pose a hazard to communities [e.g., 20, 21, 12 makes the understanding of how its thermal regime 
responds to temperature increase very relevant. Moreover, little is known about the effects of permafrost degradation on hydrological processes, moisture and related ecosystem or carbon dynamics [e.g., 22, 23, 24]. Due to the complex relationship between climate and permafrost [e.g., 25], it is therefore essential to provide continuous measurements of surface displacements at large scale and over a long-time period, indicative of the permafrost dynamics.

Here, we conduct a large-scale MT-InSAR analysis in the northeastern part of the Tibetan Plateau using both Envisat (2003-2011) and Sentinel-1 (20142019) C-band SAR data (Fig. 1) to measure the response of the permafrost's related ground deformation to atmospheric temperature increase over Tibet [e.g., 26, 27, 28.

The study area is located between the North Qaidam thrust system, in the south, and the Qilian Nan Shan thrust belt, in the north (Fig. 1). In this arid and remote part of the Tibetan Plateau with elevation ranging between $1600 \mathrm{~m}$ and $5700 \mathrm{~m}$, the mean annual ground surface temperature is between 0 and $-5^{\circ}$, the annual precipitation between $50 \mathrm{~mm}$ and $400 \mathrm{~mm}$ [27, 29] and large-scale coarse models [3, 4, 5] predict cold and continuous permafrost with a relatively thin active layer between 1 and $1.5 \mathrm{~m}$. Investigations of permafrost in the Qilian Mountains of the Heihe River Basin, show that the lowest observation of permafrost is at $3650 \mathrm{~m}$ and $3400 \mathrm{~m}$ for the south and north facing slopes, respectively, and that the active layer thickness (ALT) can be strongly variable [e.g., 27].

In this analysis, the high-resolution data set provides large-scale measurements in both ascending and descending geometries from 2003 to 2019 that allow us to analyse the deformation signals for different topographic, geomorphologic, lithological and hydrological settings and advance our understanding of the dynamics of periglacial surface processes, in an area where deployment of in-situ traditional investigation methods is difficult. 


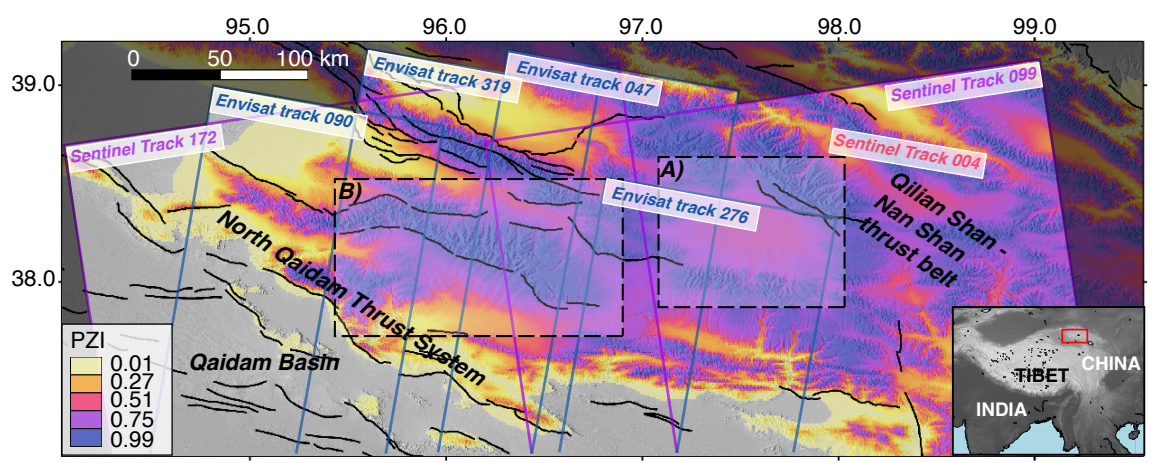

Figure 1: Surface traces of the 4 overlapping Envisat descending tracks, the Sentinel1 descending and the two Sentinel-1 ascending tracks in the northeastern part of the Tibetan plateau superimposed on the SRTM $30 \mathrm{~m}$ hill-shaded Digital Elevation Model [30] and Permafrost Zone Index (PZI) 3], ie. the probability of permafrost occurrence. Dashed-rectangles A and B delimit the two enlarged areas in the following analysis (Figs. 5 6). Black lines are regional active faults [31. Bottom right inset: regional setting and location of the study area (red box).

\section{Method}

\subsection{InSAR data processing}

We process the complete Envisat data archive along four 300-km-long and

\begin{abstract}
100-km-wide overlapping descending tracks (90, 319, 047, and 276) between 2003 and 2011, as well as three Sentinel-1 tracks (004, 172, 099) acquired in interferometric wide-swath mode ( $\sim 250 \mathrm{~km}$-width) from 2014 to 2019 , with the New Small Baselines Subset (NSBAS) processing chain [32, 33, which includes routines of the ROI_PAC software [35] (Fig. S1). Extensive details on the processing of the Envisat data can be found in Daout et al., 2019 [31. Here, we provide information about the Sentinel-1 data processing (Fig. 2), which follows a similar approach until the unwrapping step (Fig. 2. $)$. However, fine registration based on the enhanced spectral diversity method as explained in Grandin 2015 [36], is also performed to the Sentinel-1 radar images. To unwrap both short and long-baseline interferograms (Fig. S1), NSBAS allows a series of cor-
\end{abstract}




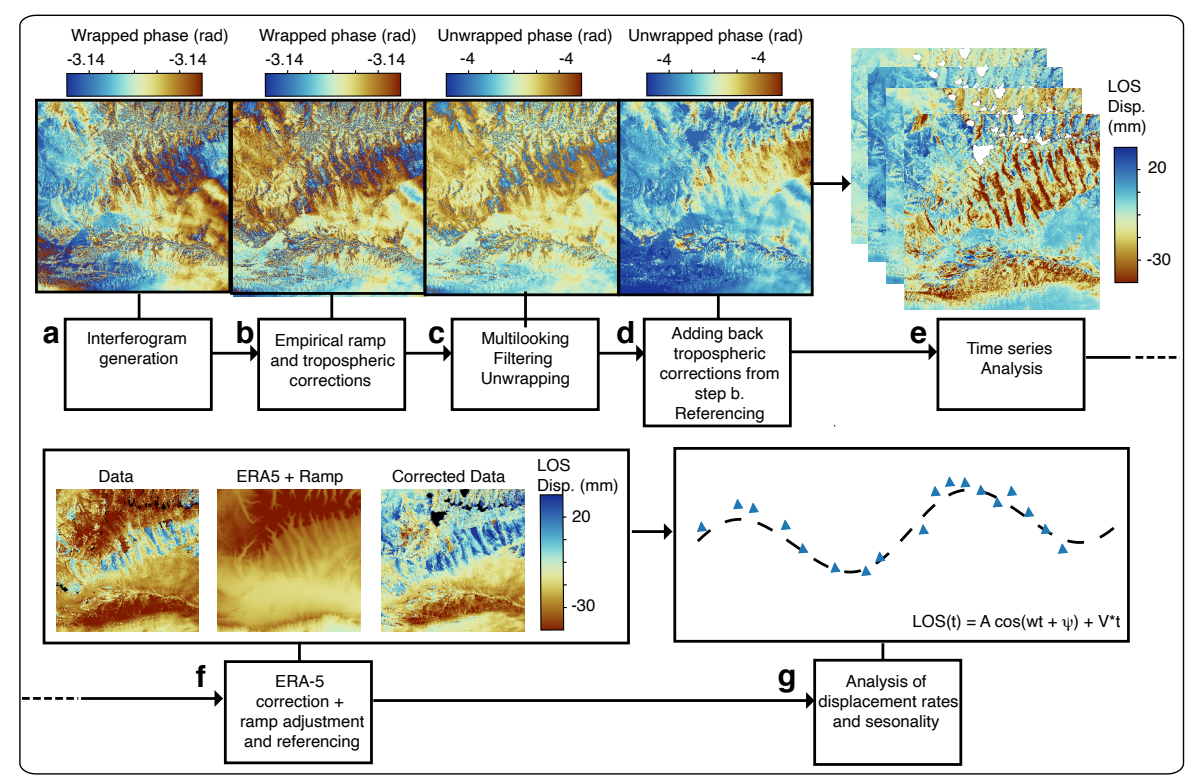

Figure 2: Illustration of the processing strategy adapted for this large mountainous area with examples from Sentinel-1 descending track 004 around the rectangle B in Fig. 1. Interferograms are processed with the New Small Baselines Subset (NSBAS) processing chain [32, 33. (a). Before the critical step of phase unwrapping, we apply empirical phase-elevation and ramp corrections in order to reduce the variability of the phase (b). After phase multi-looking, filtering and unwrapping (c), the previous corrections are reintroduced $(\mathrm{d})$ to construct the cumulative time series of the complete interferometric signal referred to the first date (e). Cumulative LOS displacements are then corrected from predictive ERA-5 atmospheric models from ECMWF 34] in order to remove the tropospheric delays (f). After correction, corrected cumulative displacement time series are decomposed into a seasonal and long-term trend $(\mathrm{g})$. Cropped interferograms are displayed in radar geometry. 
rections prior to phase unwrapping, thus significantly improving unwrapping over large areas [e.g., 37, 33, 31]. An empirical phase-elevation correction on the wrapped phase is applied to all interferograms to reduce the variability of phase. This step already reveals the signal associated with freeze-thaw cycles of the active layer in the wrapped interferograms. The heave and thaw settlement deformations of the active layer are usually associated with reversible and high-fringe rates on localised and sharp boundary areas (Fig. S2). The signal is usually spatially asymmetric, with higher gradients on one side of the basin from the other (Fig. S2). The asymmetry of the phase is a clear challenge for unwrapping as it easily creates unwrapping errors if the unwrapping path goes through the high gradients, where the signal is often subjected to aliasing, and, therefore, requires careful processing [9]. To avoid unwrapping propagating into incoherent areas (e.g snow-capped mountain ridges or areas of very high fringe rates linked for instance to permafrost's related processes), the unwrapping is performed by starting from a coherent reference pixel, and expanding progressively into areas of lower coherence [37.

After unwrapping, we re-introduce the empirical correction previously removed (in step Fig. 2b) from each interferogram (Fig. 2p), refer all interferograms to a low-elevation area within the Qaidam basin, and construct the cumulative time series, referred to the first acquisition date, on a pixel-by-pixel basis [33] (Fig. 24). The calibration point, at a low elevation within the Qaidam basin, is selected in an area with high coherence, low phase gradient and where low atmospheric turbulence or deformation is expected. Misclosure of the unwrapped interferogram network is then computed and interferograms with high residuals are re-unwrapped with high priority bridges set manually by visual inspection of the interferograms. Final time series results are masked from pixels with low misfits and elevations lower than $3400 \mathrm{~m}$, where no permafrost is expected. Cumulative LOS displacements $(\operatorname{LOS}(\mathrm{t}))$ are, afterwards corrected for tropospheric effects using the ERA-5 atmospheric models from ECMWF [34] (Fig. 2f). ERA- 5 provides estimates of temperature and water vapour partial pressure as a function of the geopotential height every hour at 137 pressure lev- 
els on a $30 \mathrm{~km}$ grid from 1979 to present. Integrated path delays at acquisition times, computed from both dry and wet delay contributions are derived at ERA5 points encompassing a SAR scene, using vertical profiles of these variables [34]. The delay is then mapped onto the radar scene using a Digital Elevation Model (DEM) and a bilinear interpolation in the horizontal direction on the vertical profiles. Jointly with the atmospheric model, a best-fitting cubical ramp is also removed from the cumulative LOS displacement in order to tight the correction to the LOS displacements and refer all maps to the same low-elevation area within the Qaidam basin. This step also aims at removing the $4-6 \mathrm{~mm} / \mathrm{yr}$ of long-wavelength tectonic convergence, between the Qaidam Basin and the north Qilian Shan, associated with the distributed slow inter-earthquake deep-seated loading of the thrusts in this area [38, 31. The corrected displacement time series are then decomposed into a seasonal and long-term trend (Fig. 2 s), such as $\operatorname{LOS}(t)=V * t+A * \cos (w * t+\phi)$, where $\mathrm{V}, \mathrm{A}$ and $\phi$ are the long-term rates, the amplitude and the timing of the seasonal displacements, respectively.

\subsection{ERA-5 atmospheric corrections}

To validate the approach and quantify the effects of the predictive ERA-5 corrections on our measurements, we compare the time series with tropospheric corrections with time series that have not been corrected with ERA-5. Without tropospheric corrections, two seasonal peaks between September and December and between January and February dominate the multi-annual LOS displacements, relative to a stable low-elevation point in the Qaidam basin, for pixels with seasonal delays higher than $3.5 \mathrm{~mm}$ (Fig. 3 a,c). In addition, the amplitude of the uncorrected seasonal signal show a clear correlation with topography at a large-scale, with highest values at higher elevations (Fig. 3 a). This behaviour reflects the long wavelength and spatially-correlated signal associated with the layering of the troposphere 12 . One could also note that, contrary to seasonal ground deformation, the sign of the seasonal delays associated to change of atmospheric conditions is dependent on the reference point's elevation. For a low elevation calibration point, atmospheric delays will increase with elevation 
in January, whereas, for a high-elevation calibration point, atmospheric delays will increase with decreasing elevation in July. A comparison of the seasonal delays with two reference points at two different elevations, therefore, provides a first estimation of the tropospheric delays (Fig. S3). After ERA-5 corrections of the atmospheric prediction (Fig. $3 \mathrm{~b}, \mathrm{~d}$ ), higher seasonal amplitudes are concentrated on specific areas with no correlation with mountain ridges and with an homogeneous timing of maximum delays, which draws a normal distribution around November. This highlights the removal of the previously dominating, likely atmospheric seasonal pattern with timing of maximum delays in JanuaryFebruary.

\section{Results}

Four descending Envisat tracks made of 102 sporadic acquisitions, as well as two ascending and one descending Sentinel-1 tracks, with a total of 248 acquisitions, illuminate at regional scale the seasonal ground displacements from 2003 to 2019 over an $80,000 \mathrm{~km}^{2}$ area of northeastern Tibet (Fig. 4).

The good spatial agreement in map view between the three independent datasets (Fig. 4) and the similarity of the LOS amplitude and velocity profiles in the overlapping areas of the two Sentinel-1 ascending tracks 172 and 099 (Fig. S4), as well as in the overlapping areas of the two Envisat descending tracks 319 and 047 (Fig. S5), confirm the reliability of the results. Histograms of differences reflect measurement errors and show normal distributions centered on zero with standard deviations of about $\sim 0.6 \mathrm{~mm}$ and $\sim 0.6 \mathrm{~mm} / \mathrm{yr}$ for Sentinel-1 LOS amplitude and velocities, respectively (Fig. S4c). For Envisat data, the histogram of differences for LOS amplitudes shows a bimodal distribution with a standard deviation of $\sim 0.9 \mathrm{~mm}$, while for Envisat LOS velocities uncertainties are about $\sim 0.7 \mathrm{~mm} / \mathrm{yr}$. Some clear outliers are also visible for Envisat data reflecting a noisier data set than Sentinel-1 (Fig. S5c). Areas where the average seasonal amplitudes exceeds $3.5 \mathrm{~mm}$ coincide with local valleys and basins between mountain ranges (Figs. S4b and S5b). 

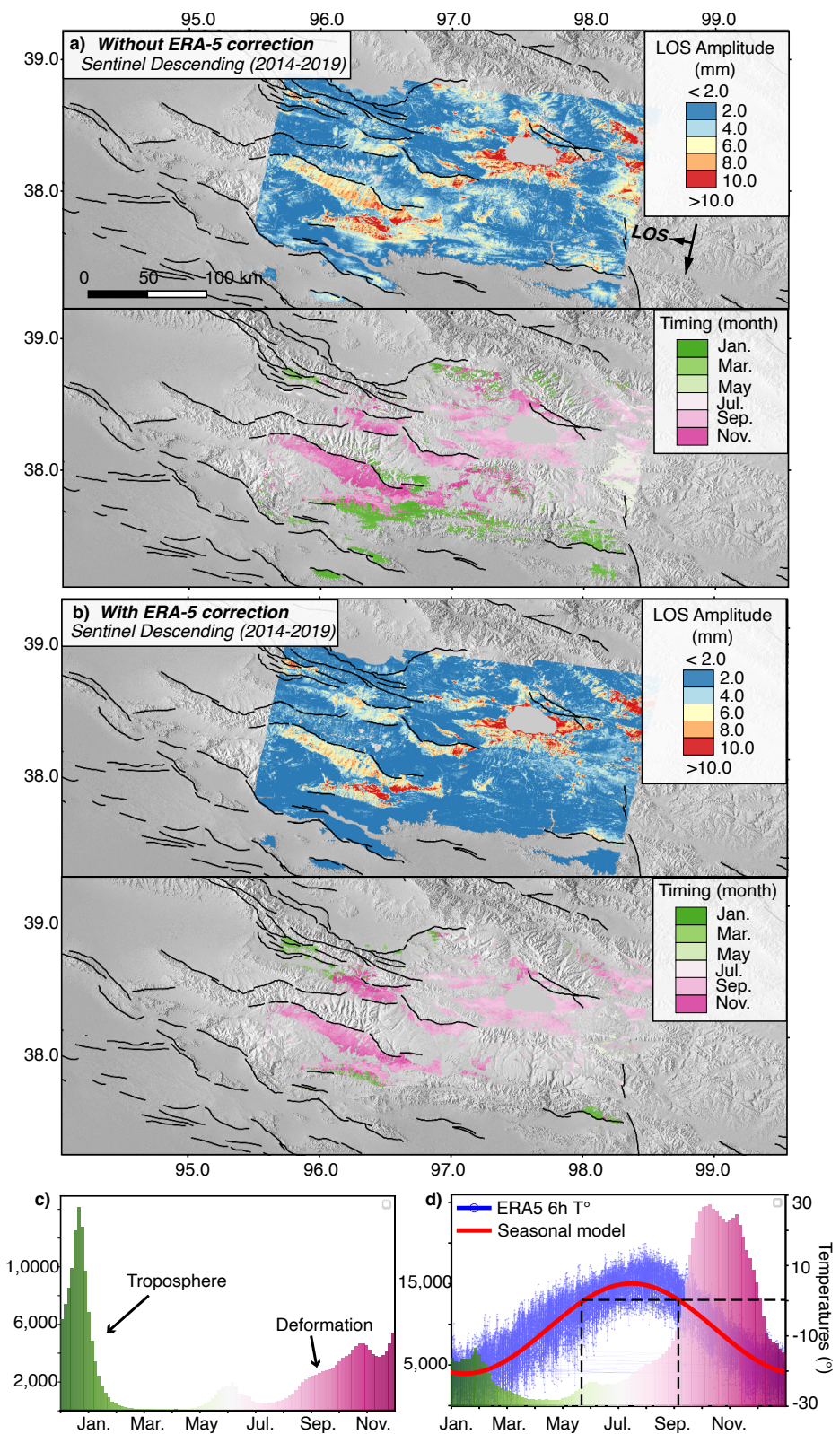

Figure 3: a) Amplitude and timing of the estimated seasonal displacements from descending Sentinel-1 track 004 without ERA-5 correction of the tropospheric delay. b) Same as (a) but after applying ERA-5 correction of the tropospheric delay. c) Histograms of timings of the maximum delays, for pixels with seasonal delays higher than $3.5 \mathrm{~mm}$, without ERA-5 correction showing two seasonal peaks in February and November, associated with the atmosphere and the freeze/thaw cycles, respectively. d) Histograms of timings of the maximum subsidence after ERA-5 corrections and comparison with the $2 \mathrm{~m}$ temperatures extracted from ERA-5 (blue dots) every $6 \mathrm{~h}$, at latitude $38^{\circ}$, longitude $96.5^{\circ}$, and an elevation of $\sim 4380 \mathrm{~m}$, and its best-fit seasonal model (red line). 


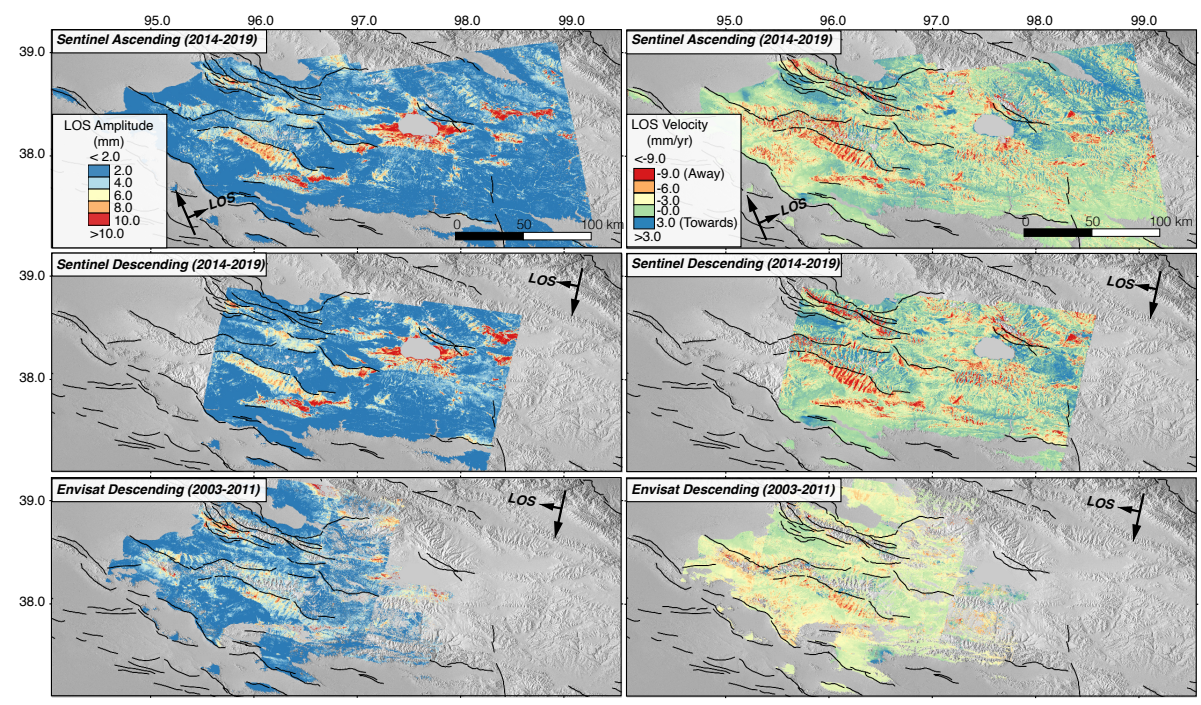

Figure 4: Left: Map of the amplitude of seasonal ground movements in the line-of-sight (LOS) directions for the ascending Sentinel-1 tracks 099 and 172 (top), descending Sentinel-1 track 004 (middle) and Envisat tracks 90, 319, 47 and 276 (bottom). Zones with a seasonal signal greater than $3.5 \mathrm{~mm}$ are discontinuously distributed on the flanks of the mountain ranges or at the shore of the internally-drained lakes. Right: Map of the pluri-annual ground velocities. Rates are large and on average away from the satellite.

Seasonal displacement maps are very similar in Sentinel-1 descending (3.1 [0.5$7.7] \mathrm{mm}$ with $95 \%$ confidence intervals) or ascending geometries $(2.6[0.5-7.2] \mathrm{mm})$ suggesting a mainly vertical seasonal deformation.

Timings of maximum subsidence for areas with seasonal amplitude higher than $3.5 \mathrm{~mm}$ are homogeneously distributed between the beginning of September and December, highlighting the removal of atmospheric artefacts (Fig. 3b,d, Fig. S3). $2 \mathrm{~m}$ air temperatures extracted from ERA-5 models have an annual average of $-8^{\circ} \mathrm{C}$, a minimum of $\sim-32^{\circ} \mathrm{C}$ in late January and a maximum of $\sim 12^{\circ} \mathrm{C}$ in July (Fig. 3 d). Contrasts between the coldest and warmest hours of the day are $20^{\circ} \mathrm{C}$. The average surface thawing and freezing onsets are on $22^{\text {nd }}$ of May and $05^{\text {th }}$ of September, respectively. Thaw settlement stops between 
September and December, thus after the average freezing onset derived from atmospheric models.

Measurements also show an anti-correlation between the amplitude of the seasonal signal and the terrain slope, as well as a correlation between the slope and the timing of maximum subsidence, with a later active layer response to the downward thawing front for areas located on steeper slopes (Fig. S6).

Negative Sentinel-1 LOS velocities dominate in areas with large seasonal amplitude (>3.5 mm) (Fig. 4), corresponding to a movement away from the satellite due to local subsidence, a horizontal motion away from the satellite or a combination of both. Pluri-annual absolute LOS velocities are lower $(-1.1[-6.4-1.7] \mathrm{mm} / \mathrm{yr})$ for Envisat descending track 047 than Sentinel-1 descending track 004 LOS velocities $(-2.1[-9.0-2.2] \mathrm{mm} / \mathrm{yr})$, indicating rates of subsidence two times higher for Sentinel-1 than for Envisat.

In the following, we will focus on the interpretation of the results on two specific landscapes types, encompassing lowland (enlargement A in Fig. 1) and high-relief (enlargement B in Fig. 1) permafrost-related processes.

\section{Interpretations}

\subsection{Lowland deformation}

The first landscape example is the area surrounding Hala lake extending $35 \mathrm{~km}$ in the EW direction and $28 \mathrm{~km}$ in the NS. The area has elevations ranging between $3840 \mathrm{~m}$ and $5720 \mathrm{~m}$. The lake is fed by rivers collecting water from the surrounding braided stream plains (Fig. 5 a). The southern part is composed of alluvial sediments in the immediate proximity of the lake, where thermokarst phenomena and polygonal cracks attest the presence of ice-rich permafrost (Fig. 5a1). The measured seasonal displacements support previous studies [e.g 6, 21, 9, 12, 11, 29], highlighting a water availability control of the amplitude of the freeze and thaw cycles. Amplitude map (Fig. 50) and profile (Fig. 5.) show a concentration of large amplitudes on shallow slopes and poordrainage areas close to the lake shores on frost-susceptible fine-grained lacustrine 

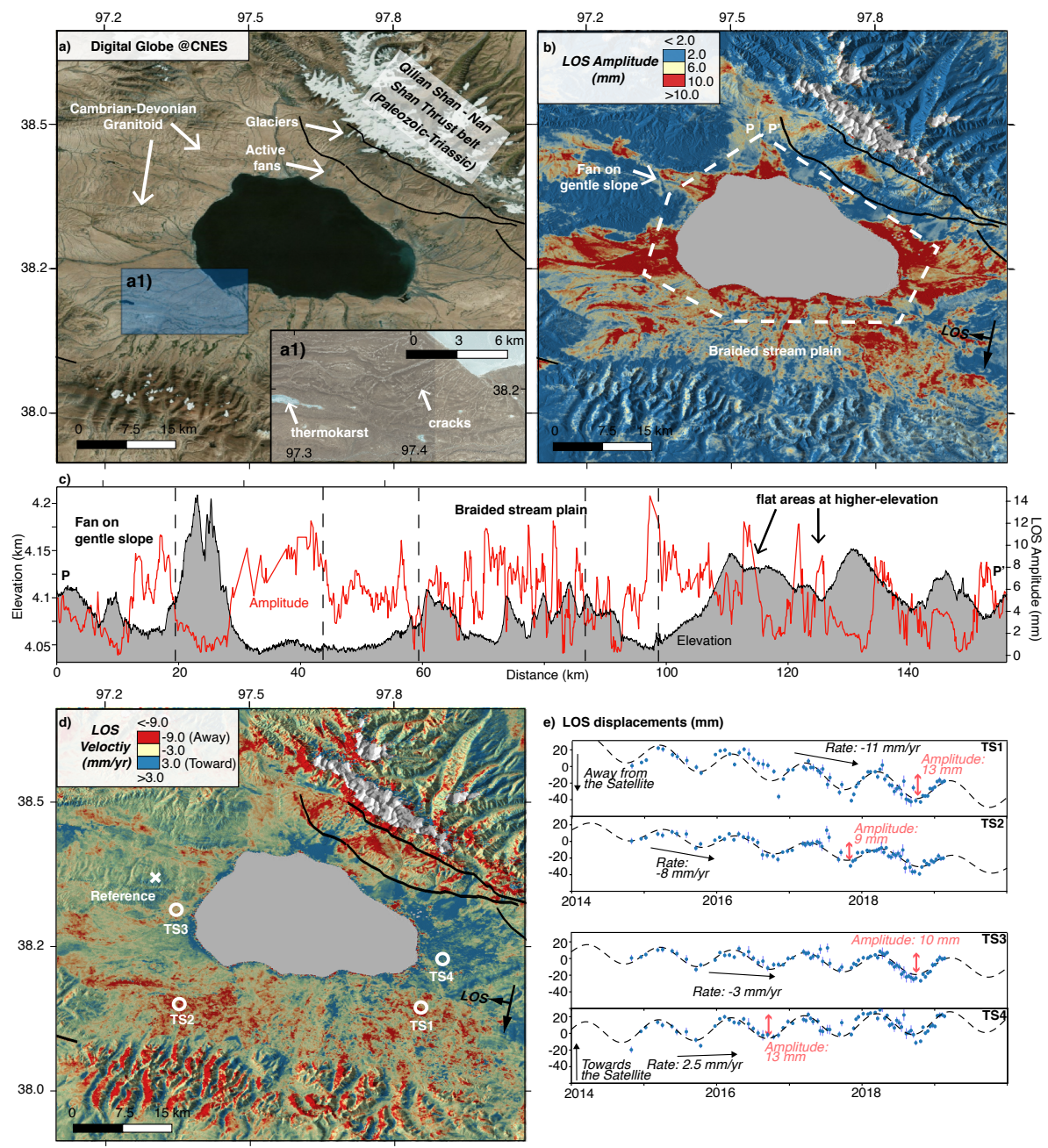

Figure 5: Enlargement around the large internally-drained Hala lake in the northeastern part of the study area (rectangle A in Fig. 1). a) Google Earth images and enlarged area $\mathrm{a}_{1}$. On the northern side, bedrock of the Southern Qilian thrusts is exposed. b) Amplitude map of the seasonal freeze/thaw cycles for descending Sentinel track 004. c) Seasonal amplitudes (red line) and elevation (black line) along profile PP' shown in (b) surrounding the lake in an anti-clockwise direction. Dashed lines indicate the start and end of segments of PP'. d) Map of the long-term ground velocity for descending Sentinel track 004. e) LOS displacement time series for the circles in (d) with best fit sine function with varying timing and a linear trend. 
or poorly-sorted fluvial sediments. For example, on the north-west side of the lake, high seasonal displacements follow very sharply the boundary of a debris fan (see Fig. 5b) and to the south of the lake, larger seasonal displacements are observed along braided streams. High amplitude concentrations are also found at the mouth of gullies collecting melt waters, along the river floodplains and on flat areas at higher elevations. We observe relatively higher amplitudes farther from the high energy transport area and lower amplitudes closer to the high energy region. In these areas, lower stream power is expected to transport finer soil particles, such as silt or fine sands, that have the highest susceptibilities for ice lensing and to frost heave due to their favourable combination of capillarity and permeability, and thus ability to retain water within the pores.

Several areas with large seasonal amplitudes (Figs. 5b,c) are affected by an overall trend away from the satellite (red areas in Figs. 5d,e). This is likely linked to a long-term cumulative thaw settlement due to a gradual loss of water/ice volume that is not fully recovered during yearly cycle [7, 9, 10. The absence of significant changes in seasonal amplitudes in comparison to the large pluri-annual trends implies that the thawing of the ice-rich permafrost near the permafrost table produces little or no changes in the excess water within the active layer. The latter may be drained away into the lake or might not provide enough water/ice content in the shallow layers to create changes of heave/thaw settlement in the next freezing and thawing seasons. In addition, a component of sediment compaction also contributes to the long-term thaw settlement and may explain the absence of proportionality between long-term subsidence and seasonal amplitude increase [e.g 39].

At the southern margin of Qilian Shan-Nan Shan thrust belts, in the glacier fore-fields, deep-seated cohesive viscous creep in perennially frozen, ice-rich debris is indicated by the "porridge-like" appearance of thick morainic deposits (Figs. 5a, Fig. 7 a). The vegetation cover at the surface indicates a rather old age of the landform with low activity (Fig. 7 a). South of those periglacial landforms, a signal towards the satellite (in blue patterns) follows very sharply the boundaries of alluvial fans and the northeastern shore of the lake in both ascending 
and descending views (Figs. 5e,e, Fig. $7 \mathrm{a}$ ). If this signal contained a horizontal component, this would indicate a motion up-slope. Since this is unfeasible and given that ascending and descending geometries have very similar signs of surface displacements, we interpret the data as a long-term surface rise. This is likely associated with an increase of water or ice volume within areas characterised by high water accumulation, fed by increase in precipitation, permafrost thawing, or glacier's retreat at higher elevations [28].

\subsection{High-relief deformation}

The high-relief Paleozoic range is bounded, in the north, by a glacier outwash plain and, in the south, by alluvial and lacustrine quaternary deposits (Fig. 6a). The elevation ranges between $3600 \mathrm{~m}$ and $5650 \mathrm{~m}$. The measurements underline again the control exerted on the magnitude of the freeze/thaw cycles by the geological material and topographic effects. The higher seasonal amplitudes are mainly concentrated on the unconsolidated sediments in the glaciers outwash plain, in the alluvial deposits or on the floodplains (Fig. 6b). However, a dependency on slope orientation of the long-term rates is visible at largescale along the various valleys, which is linked to the along slope difference of horizontal velocities induced by the slow downslope, gravitational, mass wasting processes (Fig. 6.). A large-scale horizontal motion is highlighted by the correlation between the observed LOS velocity and the terrain slope direction (Fig. 6d).

Long-term cohesive deformation of thick frozen debris masses is visible in glacier fore-fields, north of the enlarged mountain (Fig. 6a, Fig. 7b). In many cases, they are characterised by thermokarst ponds and proglacial lake formation, which emphasise the recent effects of increasing temperature trends on surface and subsurface ice in the region [e.g 26, 27, 28]. Geomorphological markers and LOS surface displacements suggest slow gravitational deformation of a few cm/yr or less of the ice-rich perennially frozen, ice-cored morainic materials as well as of peripheral glacier ice (Fig. 7 F), in agreement with expected thin and slow flowing cold glaciers in dry and high-elevated continental climatic 
conditions [40.

Comparison of time series (Fig. 6e) reveals a net increase of the displacement rates, the Sentinel-1 velocities over the period 2014-2019, being two to five times higher than those measured with Envisat data over the period 2003-2011 (Fig. 6e). In the floodplain, an increase of the seasonal amplitude is visible on some time series, highlighting an increase of water content in a saturated active layer and/or an increase of the ALT itself (Fig.6 d). However, a regional increase of inter-annual seasonal amplitude is not measured. The fact that the amplitude increase is only observed on low-angle slope pixels in the floodplains emphasises the clear control on the deformation exerted by the drainage conditions of the active layer. Anomalies are also observed, more particularly in summer 2018, where displacement time series indicate larger subsidence movements (Fig. 6e).

On the southern side of the range, the slope, away from the range, is on the whole much shallower ( $\sim 3 \%$ slope) than the transversal valley flanks $(\sim 12 \%$ slope) separating the individual ridges and oriented roughly NE-SW. Decomposition of both ascending and descending LOS velocities into a vertical and east-west $\left(\mathrm{N} 110^{\circ} \mathrm{E}\right)$ horizontal velocities is possible, here, as the horizontal velocity gradients are expected to be roughly oriented in a $\mathrm{N} 110^{\circ} \mathrm{E}$ direction, which is the most favourable orientation for detection by the satellite. Results show that for pixels with seasonal freeze/thaw cycles higher than $3.5 \mathrm{~mm}$, the $\mathrm{N} 110^{\circ} \mathrm{E}$ long-term velocities range between -26 and $18 \mathrm{~mm} / \mathrm{yr}$, while the vertical long-term velocities are within -24 and $7.5 \mathrm{~mm} / \mathrm{yr}$. The map of Fig. 8 a shows pervasive subsidence affecting all valley flanks and sedimentary basins in the whole area, in comparison to surrounding stable bedrock. The east-west motion is clearly localised on the steeper slopes of the transversal ridges, illuminating the downslope sliding of valley flanks (Fig. 8b,c). The sign of the horizontal signal correlates with the orientation of the slope and with solifluction sheet patterns visible on the optical images, from our analysis (Fig. 8b,d). Such geomorphological landforms indicate shallow mass movement of thin detached layers of homogenous and fine-grained material with the slipping plane corresponding to one of the fissures created by the ice [42, 6, 21]. The anti-correlation 


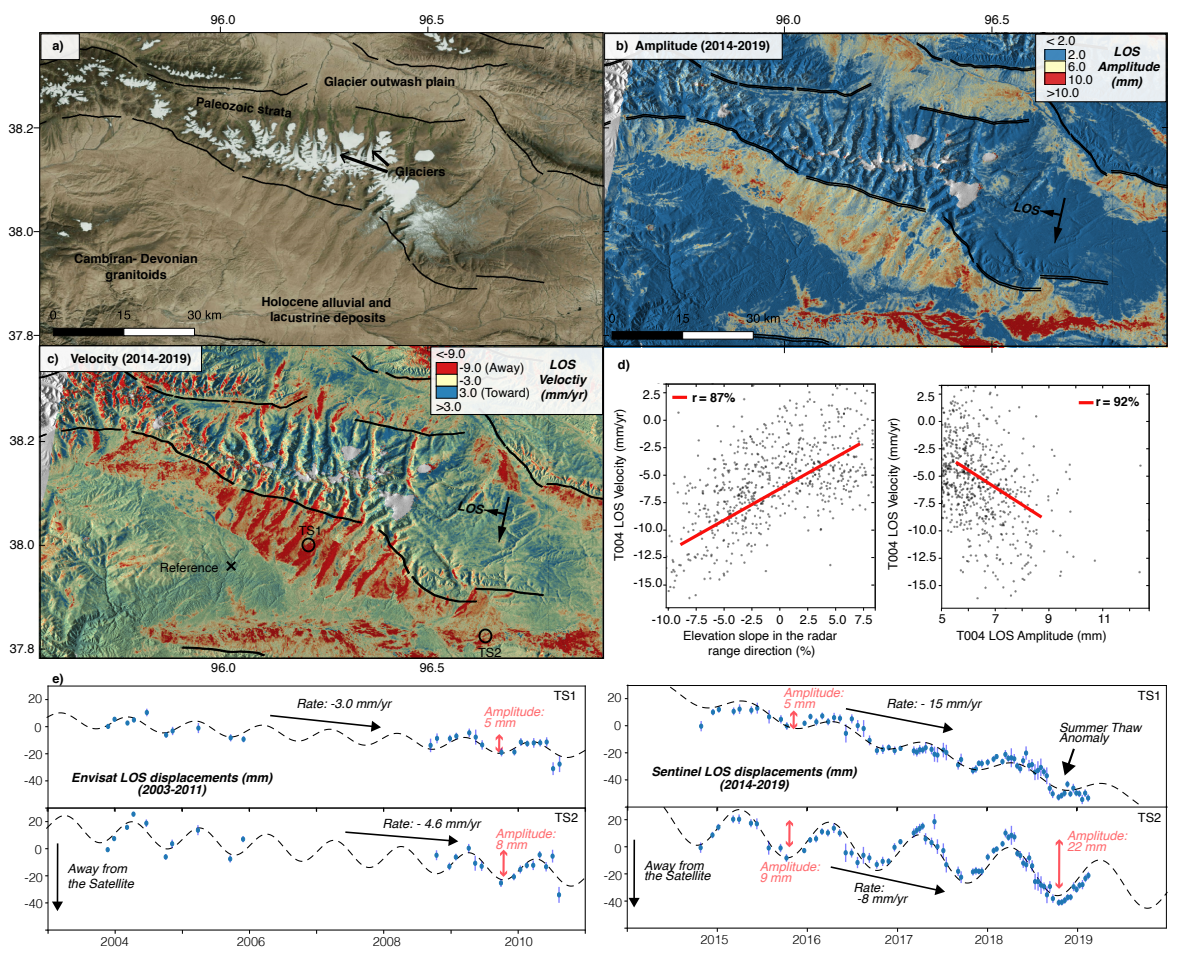

Figure 6: Enlargement around a high-relief range in the western part of the study area (rectangle B in Fig. 1). a) Google Earth imagery. b) Amplitude of the seasonal freeze/thaw cycles from descending Sentinel track 004. c) Long-term ground velocity from track 004. d) Scatter plots showing the correlation in enlargement area between the LOS velocity of track 004 and terrain slope along radar range direction (left) and the amplitude of seasonal movements (right) for pixels with slope higher than $3 \%$. e) LOS displacement time series for the two circles in c) derived from both Envisat (2003-1011) and Sentinel-1 (2014-2019) data with best fit sine function with varying timing and a linear trend, emphasising the increase of both pluri-annual rates and seasonal amplitudes from 2003 to today. 


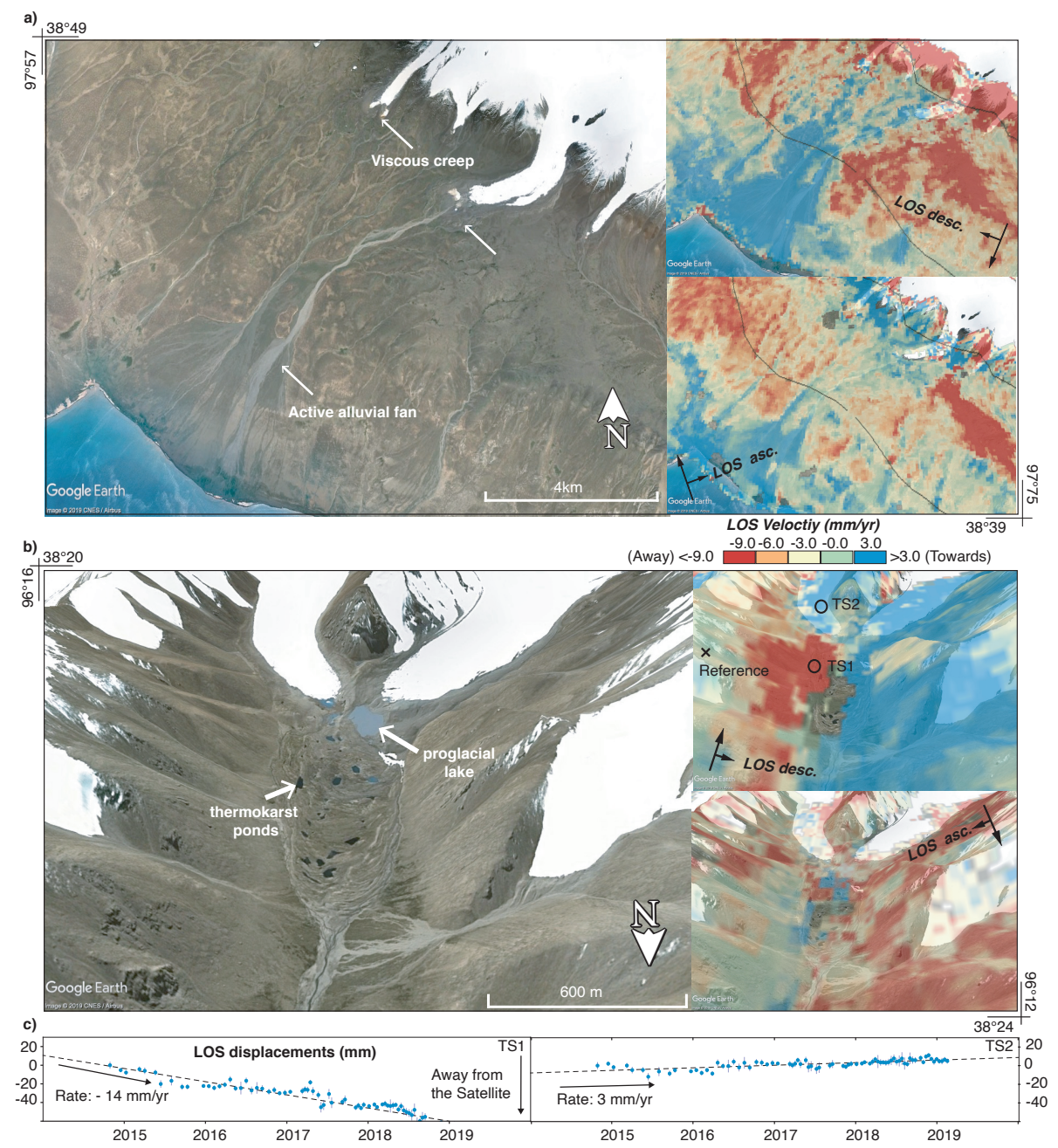

Figure 7: Enlargement at the bottom of Qilian Shan-Nan Shan thrust belts, north of the Hala lake of the Fig. 5 (a) and at the northern flank of the mountains of Fig. 6 at the fore-field of the glaciers (b). a) Google Earth imagery side-by-side of the LOS velocities of the descending track 004 (top-right) and the ascending track 099 (bottom-right). Ascending and descending velocities are very similar indicating a mainly vertical deformation. b) Google Earth imagery side-by-side of the LOS velocities of the descending track 004 (top-right) and the ascending track 172 (bottomright). Ascending and descending velocities are almost of opposite signs indicating a mainly horizontal deformation. c) Two time series of the descending LOS surface displacements marked as circles on the velocity map in (b). Creep rates of both glaciers and frozen debris landforms are of the order of the $\mathrm{cm} / \mathrm{yr}$ or less. 


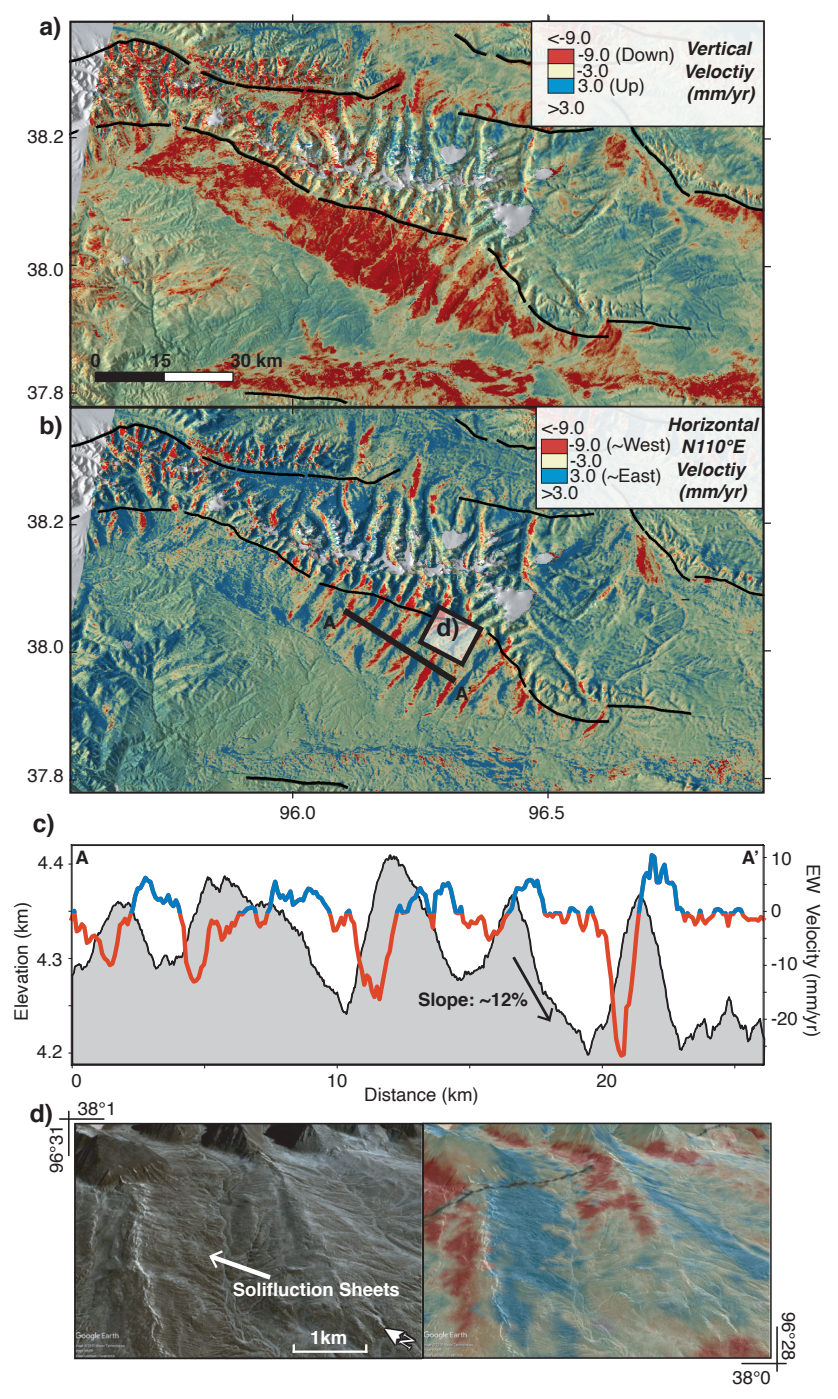

Figure 8: Vertical (a) and east-west $\left(\mathrm{N} 110^{\circ} \mathrm{E}\right)(\mathrm{b})$ decomposition of the velocity of the area B in Fig. 1 obtained from inversion of the two ascending and the descending velocities of the Sentinel- 1 data. c) $\mathrm{N} 110^{\circ} \mathrm{E}$ velocities (eastern motion in blue, western motion in red) along profiles AA' shown in (b) illuminating the downslope sliding of solifluction sheets within the individual transversal ridges of valley flanks. d) Enlargement of the east-west velocity, side-by-side to a Google Earth imagery, on individual ridges showing the correlation of the signal with solifluction sheet patterns. 
between LOS velocity and the amplitude of the seasonal movements (Fig. 6d) highlights the control played by the water concentration and the amplitude of the freeze/thaw cycles on the intensity of the mass movements 6]. Here again, the soil properties and water content in the layers of loose sediments appear to directly influence the rates of the horizontal ground deformations.

\section{Discussions and conclusion}

\subsection{Permafrost's freeze/thaw cycles monitoring with InSAR}

With an unprecedented spatial and temporal sampling, MT-InSAR data provide insights into the response of the permafrost to temperature increase over Tibet. The higher spatial continuity of the Sentinel-1 results in comparison to Envisat highlights the significant benefits and potential of the newly launched Sentinel-1 data to drastically decrease temporal decorrelation affecting the interferometric signal for fast-moving surface processes and to monitor the spatial and inter-annual variations of deformation at high-resolution.

Moisture cycle is likely the main source of error when measuring the freezethaw cycle with InSAR [43, 44]. The increase of moisture during a thaw event decreases the penetration of the electromagnetic wave into the ground by a factor that can reach 10-20\% of the wavelength, and therefore under-estimate the amplitude of the measured thaw settlements. Large fluctuations of soil water content in coarse or high bulk density material with low organic matter [e.g 45 will, therefore, increase this effect. In addition, the asymmetry of the moisture deformation, with fast soil wetting and slow soil drying, creates systematic decorrelation or possible unwrapping errors of the interferometric signal during wet events, which may lead to time series analysis biases. In order to explore the stability of the time series analysis, and investigate the possible presence of biases, we perform time series inversions with various interferometric networks (Fig. S7, S8). The analysis show good robustness of the linear velocity retrieval after changing the interferometric network and, more particularly, after removing short-temporal baselines interferograms. Major differences only 
arise when performing a time series analysis with an interferometric network constructed only with short-baselines interferograms connecting two successive acquisitions (Fig. S7, S8). This confirms the analysis of Andari et al., 2020 [46 showing that short baseline interferograms are the least reliable for deformation retrieval. Biases induced by the integration of short temporal baselines are not only observed in high-moisture regions, but also on the mountain peaks, likely linked to snow and to systematic decorrelations or unwrapping errors induced by the abrupt changes of ground properties.

The measurements presented in this study show amplitudes and timings of maximum subsidence that vary spatially and inter-annually, indicating that other factors than air temperature are important in determining the freeze/thaw state of the active layer [39, 21, 47]. To emphasise this point, we provide in Fig. S9, time series of surface displacements modeled with the Stefan equations, where the deformation is proportional to the square root of the cumulative degree day of thawing or freezing extracted from the ERA-5 measurements of Fig. 3d. A degree-day model imposes uniform heave and thaw onsets on the whole area based on one single temperature, and, therefore, does not approximate correctly the data at a regional scale. In addition, on steep ground as the expansion is normal to the slope and the collapse is more or less vertical, the LOS surface displacements deviate from the Stefan prediction. Care must, therefore, be taken when prescribing the evolution of the deformation in the time series analysis with a degree-day model because of the spatial variability of the freezing and thawing onset lags. Gridded temperatures records from reanalyses or remote sensing data could be used to better capture the spatial variability of the ground temperature. However, and as shown from the time series of Figs. 5e, 6e, maps of the timing of maximum seasonal displacements (Fig. 3p), or observed correlations between seasonal amplitudes, local slope, and timing of maximum seasonal subsidence (Fig. S6), there is a spatial variability of seasonal delays over the same regions that cannot solely be explained by changes in surface temperatures. In addition, the large DEM errors found by some studies using Sentinel-1 data, which have, however, a good baseline control, reflect the 
trade-offs of the deformation model with other parameters of the inversion, such as a DEM error term. The analysis of this paper shows that a simple sinusoidal model allows to map and interpret the lateral variability of maximum seasonal deformation and separate seasonal signals associated with tropospheric delays from seasonal ground deformation (Fig. 3).

\subsection{Seasonal effects}

The analysis highlights a late point of change from subsidence to heave at the end of the year (Fig. 3 b,d). To further illustrate this, we compute the de-trended and normalised seasonal signal over a 12 months period, $(\operatorname{LOS}(t)-V * t) / A)$, where $\operatorname{LOS}(t)$ are the time series of LOS displacements for each pixel and $A$, $V$, are the inverted amplitudes and velocities previously obtained (Fig. 9). During the frozen period between February to June, the surface remains stable. In May/June (once surface snow disappears), as surface temperatures rapidly increase above $0^{\circ} \mathrm{C}$, large vertical subsurface temperature gradients and heat fluxes build up and rapid one-sided downward thawing in the active layer with corresponding thaw settlement takes place (Figs. 5e, 6e, 91. Around September/October, maximum thaw depths are reached and little to no more phase change occurs. Then, the two-sided freezing starts in November/December and lasts until February/March. The process is fast downwards from the surface because of high temperature gradients and correspondingly high heat losses, but slow upwards from the permafrost table with low temperature gradients and heat fluxes. When the downward penetrating freezing front approaches the upward migrating freezing front at depths, pore water in the still unfrozen zone between the two freezing fronts becomes pressurised, stabilising and prolonging the phase change with corresponding latent heat and extended zero-curtain effects. While mostly interstitial ice with little or no expansion of total soil volume had formed in the top soil during early fall, ice segregation takes place during December/January at depth (near the permafrost table), involving volume expansion and frost heave. Eventually, as the remaining unfrozen water between the two freezing fronts gets under pressure and lowers its freezing temperature, 
the process of ice segregation and complete freezing is further delayed. Comparison between the high-relief region and the lowland area in Fig. 9, also indicate a more delayed frost heave for the high relief area. Around the Hala lake, the frozen period is between February and June, while the cumulative maximum ground settlement is reached in October. For the high-relief area, the frozen period is shrunk compared to the lowland region between April and June, and the maximum settlement is around November.

In comparison, Liu et al., 2017 [48] have shown with in-situ observations of the active-layer properties in the Tien Shan that active-layer freezing at depth, near the permafrost table, can be delayed by several months with respect to the onset of freezing from the surface and takes place around the end of the year. Boreholes measurements in the northern and more vegetated part of the Qilian Shan [29], also show a downward penetration of the freezing fronts in the active layer of about $1.2 \mathrm{~m}$ in November-December, in agreement with the timing of lowest surface elevation measured in this study (Figs. 3d, 9). Several studies also highlight the presence of ice-rich layers in the ground, and more particularly, of segregated ice for silty clay and sandy gravel in valley-bottom geomorphological settings [e.g 14, 15]. Permafrost in shallow areas in the studied region can reasonably be assumed to be similarly rich in ice, especially at the permafrost table, in the presence of fluvial or lacustrine frost-susceptible fine or poorly-sorted materials (silt, sand, sandy gravels).

In this northeastern part of the Tibetan Plateau, large-scale coarse models predict cold and continuous permafrost [3, 4, 5. However, the analysis reveals that large $(>3.5 \mathrm{~mm})$ frost heave and thaw settlements are only concentrated on undrained basins or on south-exposed flanks covered by sedimentary deposits (Fig. 4). We suggest that the spatial localisation of large freeze/thaw cycles reflects the heterogeneous distribution of the excess water in frost-susceptible materials that is controlled by the soil property and by the contrasts between slopes and nearly flat areas of the Tibetan Plateau. Permafrost's active layer freezing and thawing is widespread but frost heave and thaw subsidence magnitude depends on excess subsurface ice. In this dry and desertic continental area, 


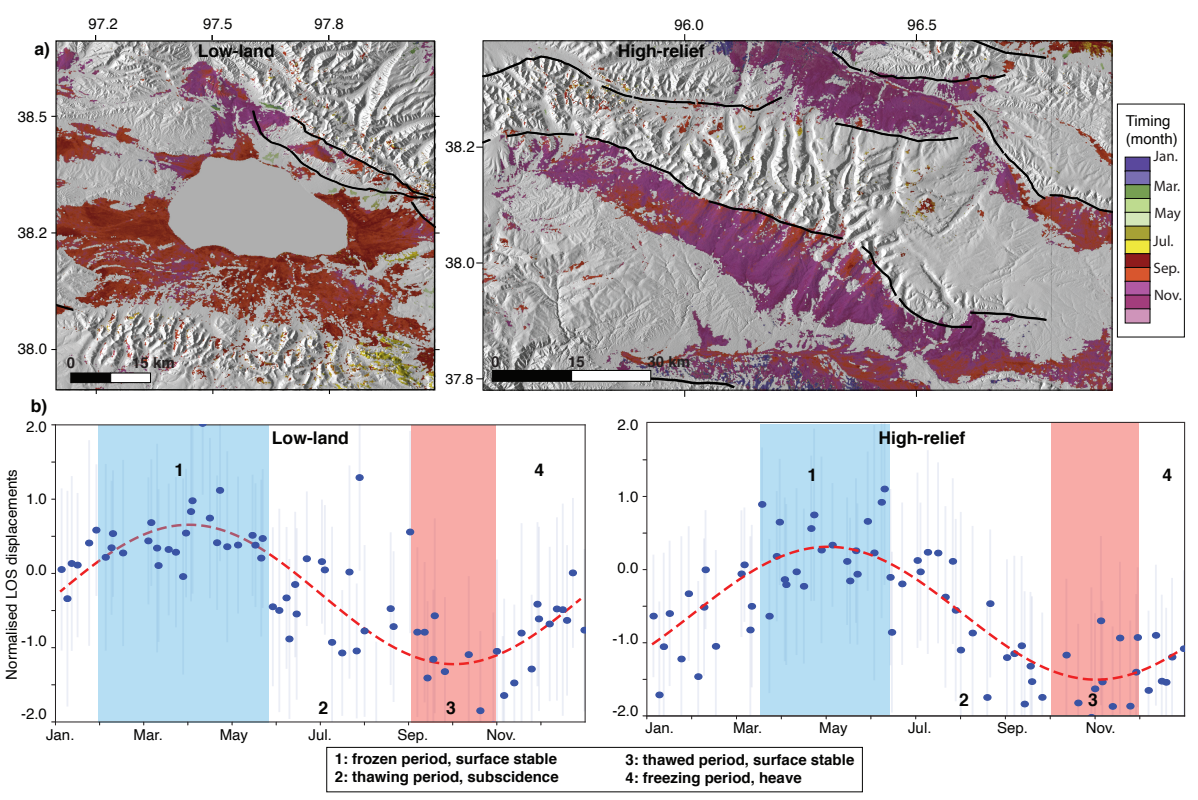

Figure 9: a) Timings of the freeze/thaw cycles for the lowland (left, Fig. 5 and highrelief (right, Fig. 6) areas, for Sentinel-1 descending track 004, masked from pixels with amplitude of seasonal displacement inferior to $3.5 \mathrm{~mm}$. b) Normalised seasonal evolution at data acquisition times (filled circle are median values for all pixels while thin vertical bars are standard deviation for all pixels) wrapped between January and December over the lowland (left) and high relief (right) areas, for pixels with seasonal displacements higher than $3.5 \mathrm{~mm}$. The seasonal models are in red dashed lines and estimates of frozen and thawed periods are the blue and red shaded regions, respectively. During the frozen period (1), the surface remains more or less stable until the onset of thaw/subsidence (2) from the surface with positive air temperatures in about early June. During the thawed period (3), maximum thaw depths are reached and little to no more phase change occurs. The two-sided freezing (4) starts in November/December and lasts until February/March, when maximum heave rates are observed from ice segregation at depth. 
large seasonal amplitudes detected with InSAR reflect soils with high subsurface water contents or where the deepening of the thawing front reaches ice-rich layers. The findings also suggest that the seasonal thawing front deepening at the permafrost table is occurring over a widespread region, with local variations depending on snow cover, hydrology, micro-topography or vegetation cover, and that the delay observed in active-layer freezing is not only a localised occurrence.

\subsection{Long-term ground subsidence}

The analysis shows significant long-term subsidence trends over areas that undergo large seasonal heave and thaw settlement at a regional scale (Figs. 4, 8 a). If this subsidence were linked to an increase of ALT alone, we would observe simultaneously a regional increase of inter-annual seasonal amplitude at regional case, which is not the case else than few areas. In light of the large seasonal thaw-subsidence delayed at the end of the year, of the high long-term subsidence rates, and of the increase in long-term trends from Envisat to Sentinel-1 measurement, we infer that the seasonal thawing front is likely reaching the ice-rich layers at the bottom of the active layer and link the observed pervasive subsidence rates to an ice-loss in the Northeastern Tibetan Plateau permafrost. This phenomenon, also called isotropic thaw subsidence, has been documented by other authors in Alaska [49, 50, who highlighted limited correlation between increasing air temperature and ALT above ice-rich permafrost, but widespread and important $(\sim \mathrm{cm} / \mathrm{yr})$ subsidence of the ground surface associated with warmer winter, increased snow depth, and deeper thaw penetration into the ice-rich transient layers in summer. Permafrost degradation rate and ice volume loss cannot be inferred from the measures subsidence rates as it depends on many factors such as ice content or soil compaction. However, this MT-InSAR study highlights the benefits of such regional measurements to map the lateral variability of the ground deformation dynamic. More particularly, it shows that the pluri-annual subsidence and thaw settlement of the ground is stronger for regions where relief is higher, as there, the water is well-drained and the loss of ice/water volume causes ground subsidence at rates of up to 
$2 \mathrm{~cm} / \mathrm{yr}$ (Fig. 8a). Conversely, measurements reveal that at low-elevation and internally-drained areas, the deformation is more complex due to the combination of temperature and moisture increase and that local measurements must be interpreted carefully. In lowland regions, seasonal amplitudes may increase and/or uplift may happen as the excess meltwater pools and triggers an increase of segregation ice near the permafrost table (Fig. 5 d,Fig. 6c).

The complexity of the data emphasises that caution is required in interpreting the signal in the context of atmospheric temperature increase over Tibet due to the multiple interactions between temperature increase, drainage properties, vegetation and moisture capacity of the terrain 25. Care must also be taken when drawing direct links between deformation amplitude and ALT, as also recently proposed in many studies, due to the spatial variability of the drainage and water capability of the soil of any thickness. Our findings show that a key parameter for permafrost related deformation seems to be the slope, which controls the distribution and the evolution of the excess water and may now, therefore, be included in large-scale models of permafrost distribution and degradation.

\subsection{Relation with the long-term evolution of the Tibetan Plateau}

The flatness of the Tibetan plateau has been the center of numerous debates on the long-term mechanisms that smooth out irregularities in topography and crustal thickness [e.g 2]. The importance of surface processes has been sometimes dismissed because of the low erosion rates and low drainage networks associated with the aridity of the area. However, under those climatic conditions, periglacial mass-wasting processes may dominate other erosional mechanisms. Our findings show that in this active and rugged part of the Tibetan plateau, where relief reduction is in competition with active tectonics [2] and where there is very little deep-rooted vegetation to prevent downslope massmovements, periglacial surface processes, with LOS ground motion of the order of a centimeter per year, are stronger than any tectonic signals that could be expected along the North Qaidam thrusts or the southern part of the Qilian 
Shan [38. This result shows that it is critical to delineate the areas affected by periglacial related deformation to avoid erroneous interpretations of the tectonic loading along faults in cold regions. It also demonstrates that, in addition to low energy rivers transport and the internal drainage characteristic of this part of the Tibetan Plateau that disconnect inter-mountains catchment basins form the foreland outlets, periglacial processes, such as solifluction, participate in relief smoothing by moving loose sediments from the high ranges to the lowland regions.

\section{Acknowledgments}

This research was supported by the Natural Environment Research Council through the Looking into the Continents from Space (LiCS) large grant (NE/K011006/1) and the Centre for the Observation and modeling of Earthquakes, Volcanoes and Tectonics (COMET). M-P.D's contribution was supported by the CNES (DAT-S1 CNES-APR-180027).

\section{Data Availability}

The maps of Fig. 3 are provided as KMZ in the supplements.

\section{References}

[1] M. Fort, B. van Vliet-Lanoe, Permafrost and periglacial environment of western Tibet, Landform analysis 5 (2007) 25-29.

[2] J. Liu-Zeng, P. Tapponnier, Y. Gaudemer, L. Ding, Quantifying landscape differences across the Tibetan plateau: Implications for topographic relief evolution, Journal of Geophysical Research: Earth Surface 113 (F4).

[3] S. Gruber, Derivation and analysis of a high-resolution estimate of global permafrost zonation, The Cryosphere 6 (1) (2012) 221. 
[4] Y. Qin, T. Wu, L. Zhao, X. Wu, R. Li, C. Xie, Q. Pang, G. Hu, Y. Qiao, G. Zhao, et al., Numerical modeling of the active layer thickness and permafrost thermal state across qinghai-Tibetan plateau, Journal of Geophysical Research: Atmospheres 122 (21) (2017) 11-604.

[5] J. Obu, S. Westermann, A. Bartsch, N. Berdnikov, H. H. Christiansen, A. Dashtseren, R. Delaloye, B. Elberling, B. Etzelmüller, A. Kholodov, et al., Northern hemisphere permafrost map based on TTOP modelling for 2000-2016 at $1 \mathrm{~km} 2$ scale, Earth-Science Reviews.

[6] B. Van Vliet-Lanoë, Frost effects in soils, Soils and quaternary landscape evolution (1985) 117-158.

[7] L. Liu, T. Zhang, J. Wahr, InSAR measurements of surface deformation over permafrost on the North Slope of Alaska, J. Geophys. Res.: Earth Surface 115 (F3).

[8] L. Liu, K. Schaefer, A. Chen, A. Gusmeroli, H. Zebker, T. Zhang, Remote sensing measurements of thermokarst subsidence using InSAR, Journal of Geophysical Research: Earth Surface 120 (9) (2015) 1935-1948.

[9] S. Daout, M.-P. Doin, G. Peltzer, A. Socquet, C. Lasserre, Large scale InSAR monitoring of permafrost freeze-thaw cycles on the Tibetan Plateau, Geophys. Res. Lett.

[10] J. Chen, L. Liu, T. Zhang, B. Cao, H. Lin, Using persistent scatterer interferometry to map and quantify permafrost thaw subsidence: A case study of Eboling mountain on the Qinghai-Tibet plateau, Journal of Geophysical Research: Earth Surface 123 (10) (2018) 2663-2676.

[11] L. Rouyet, T. R. Lauknes, H. H. Christiansen, S. M. Strand, Y. Larsen, Seasonal dynamics of a permafrost landscape, Adventdalen, Svalbard, investigated by InSAR, Remote Sensing of Environment 231 (2019) 111236. 
[12] B. Dini, S. Daout, A. Manconi, S. Loew, Classification of slope processes based on multitemporal dInSAR analyses in the Himalaya of NW Bhutan, Remote Sensing of Environment 233 (2019) 111408.

[13] A. Bartsch, M. Leibman, T. Strozzi, A. Khomutov, B. Widhalm, E. Babkina, D. Mullanurov, K. Ermokhina, C. Kroisleitner, H. Bergstedt, Seasonal progression of ground displacement identified with satellite radar interferometry and the impact of unusually warm conditions on permafrost at the Yamal Peninsula in 2016, Remote Sensing 11 (16) (2019) 1865.

[14] W. Qingbai, L. Yongzhi, Z. Jianming, T. Changjiang, A review of recent frozen soil engineering in permafrost regions along Qinghai-Tibet highway, China, Permafrost and Periglacial Processes 13 (3) (2002) 199-205.

[15] M. Wei, C. Guodong, W. Qingbai, Construction on permafrost foundations: lessons learned from the Qinghai-Tibet railroad, Cold Regions Science and Technology 59 (1) (2009) 3-11.

[16] C. Wang, Z. Zhang, H. Zhang, B. Zhang, Y. Tang, Q. Wu, Active layer thickness retrieval of Qinghai-Tibet permafrost using the TerraSAR-X InSAR technique, IEEE Journal of Selected Topics in Applied Earth Observations and Remote Sensing 11 (11) (2018) 4403-4413.

[17] G. Yin, H. Zheng, F. Niu, J. Luo, Z. Lin, M. Liu, Numerical mapping and modeling permafrost thermal dynamics across the Qinghai-Tibet engineering corridor, China integrated with remote sensing, Remote Sensing 10 (12) (2018) 2069.

[18] Z. Zhang, M. Wang, Z. Wu, X. Liu, Permafrost deformation monitoring along the Qinghai-Tibet plateau engineering corridor using InSAR observations with multi-sensor SAR datasets from 1997-2018, Sensors 19 (23) (2019) 5306.

[19] L. Yuan, L. Zhao, R. Li, G. Hu, E. Du, Y. Qiao, L. Ma, Spatiotemporal characteristics of hydrothermal processes of the active layer on the central 
and northern Qinghai-Tibet plateau, Science of The Total Environment (2020) 136392.

[20] S. Gruber, M. Hoelzle, W. Haeberli, Permafrost thaw and destabilization of alpine rock walls in the hot summer of 2003, Geophysical Research Letters $31(13)$.

[21] W. Haeberli, B. Hallet, L. Arenson, R. Elconin, O. Humlum, A. Kääb, V. Kaufmann, B. Ladanyi, N. Matsuoka, S. Springman, et al., Permafrost creep and rock glacier dynamics, Permafrost and Periglacial Processes 17 (3) (2006) 189-214.

[22] F. E. Nelson, O. A. Anisimov, N. I. Shiklomanov, Subsidence risk from thawing permafrost, Nature 410 (6831) (2001) 889.

[23] G. Cheng, T. Wu, Responses of permafrost to climate change and their environmental significance, Qinghai-Tibet plateau, Journal of Geophysical Research: Earth Surface 112 (F2).

[24] J. Liu, S. Wang, Y. Huang, Effect of climate change on runoff in a basin with mountain permafrost, northwest China, Permafrost and Periglacial Processes 18 (4) (2007) 369-377.

[25] D. Riseborough, N. Shiklomanov, B. Etzelmüller, S. Gruber, S. Marchenko, Recent advances in permafrost modelling, Permafrost and Periglacial Processes 19 (2) (2008) 137-156.

[26] Q. You, J. Min, Y. Jiao, M. Sillanpää, S. Kang, Observed trend of diurnal temperature range in the Tibetan plateau in recent decades, International Journal of Climatology 36 (6) (2016) 2633-2643.

[27] B. Cao, T. Zhang, X. Peng, C. Mu, Q. Wang, L. Zheng, K. Wang, X. Zhong, Thermal characteristics and recent changes of permafrost in the upper reaches of the Heihe river basin, western China, Journal of Geophysical Research: Atmospheres 123 (15) (2018) 7935-7949. 
[28] S. Bibi, L. Wang, X. Li, J. Zhou, D. Chen, T. Yao, Climatic and associated cryospheric, biospheric, and hydrological changes on the Tibetan plateau: a review, International Journal of Climatology 38 (2018) e1-e17.

[29] Q. Wang, H. Jin, T. Zhang, B. Cao, X. Peng, K. Wang, X. Xiao, H. Guo, C. $\mathrm{Mu}, \mathrm{L}$. Li, Hydro-thermal processes and thermal offsets of peat soils in the active layer in an alpine permafrost region, NE Qinghai-Tibet plateau, Global and Planetary Change 156 (2017) 1-12.

[30] T. G. Farr, P. A. Rosen, E. Caro, R. Crippen, R. Duren, S. Hensley, M. Kobrick, M. Paller, E. Rodriguez, L. Roth, D. Seal, S. Shaffer, J. Shimada, J. Umland, M. Werner, M. Oskin, D. Burbank, D. Alsdorf, The shuttle radar topography mission, Reviews of Geophysics 45 (2007) 1-33. doi:10.1029/2005RG000183.1. INTRODUCTION.

[31] S. Daout, H. Sudhaus, T. Kausch, A. Steinberg, B. Dini, Interseismic and postseismic shallow creep of the north Qaidam thrust faults detected with a multitemporal InSAR analysis, Journal of Geophysical Research: Solid Earth 124 (7) (2019) 7259-7279.

[32] M.-P. Doin, F. Lodge, S. Guillaso, R. Jolvet, C. Lasserre, G. Ducret, R. Grandin, E. Pathier, V. Pinel, Presentation of the small baseline NSBAS Processing chain on a case example : The Etna deformation monitoring from 2003 to 2010 using Envisat data., Proc. esaFringe.

[33] M.-P. Doin, C. Twardzik, G. Ducret, C. Lasserre, S. Guillaso, S. Jianbao, InSAR measurement of the deformation around Siling Co Lake: Inferences on the lower crust viscosity in central Tibet, J. Geophys. Res.: Solid Earth 120 (7) (2015) 5290-5310.

[34] R. Jolivet, R. Grandin, C. Lasserre, M.-P. Doin, G. Peltzer, Systematic InSAR tropospheric phase delay corrections from global meteorological reanalysis data, Geophys. Res. Lett. 38 (17). 
[35] P. A. Rosen, S. Hensley, G. Peltzer, M. Simons, Updated repeat orbit interferometry package released, Eos, Transactions American Geophysical Union 85 (5) (2004) 47-47.

[36] R. Grandin, Interferometric Processing of SLC Sentinel-1 TOPS Data, Fringe 2015 (731) (2015) 36. doi:10.1109/TGRS.2015.2497902.

[37] R. Grandin, M.-P. Doin, L. Bollinger, B. Pinel-Puysségur, G. Ducret, R. Jolivet, S. N. Sapkota, Long-term growth of the Himalaya inferred from interseismic InSAR measurement, Geology 40 (12) (2012) 1059-1062.

[38] S. Liang, W. Gan, C. Shen, G. Xiao, J. Liu, W. Chen, X. Ding, D. Zhou, Three-dimensional velocity field of present-day crustal motion of the Tibetan Plateau derived from GPS measurements, J. Geophys. Res. 118 (10) (2013) 5722-5732.

[39] Gruber, S., Ground subsidence and heave over permafrost: hourly time series reveal interannual, seasonal and shorter-term movement caused by freezing, thawing and water movement, Cryosphere, 14(4) (2020).

[40] W. Haeberli, C. Burn, Natural hazards in forests: Glacier and permafrost effects as related to climate, Environmental Change and Geomorphic Hazards in Forests 9 (2002) 167.

[41] P. J. Williams, An investigation into processes occurring in solifluction, American Journal of Science 257 (7) (1959) 481-490.

[42] C. Harris, Periglacial mass-wasting: a review of research, Geo Abstracts, 1981.

[43] F. De Zan, A. Parizzi, P. Prats-Iraola, P. López-Dekker, A sar interferometric model for soil moisture, IEEE Transactions on Geoscience and Remote Sensing 52 (1) (2013) 418-425.

[44] S. Zwieback, X. Liu, S. Antonova, B. Heim, A. Bartsch, J. Boike, I. Hajnsek, A statistical test of phase closure to detect influences on DInSAR 
deformation estimates besides displacements and decorrelation noise: Two case studies in high-latitude regions, IEEE Transactions on Geoscience and Remote Sensing 54 (9) (2016) 5588-5601.

[45] Q. Wang, Q. Yang, H. Guo, X. Xiao, H. Jin, L. Li, T. Zhang, Q. Wu, Hydrothermal variations in soils resulting from the freezing and thawing processes in the active layer of an alpine grassland in the Qilian mountains, northeastern Tibetan Plateau, Theoretical and Applied Climatology 136 (34) (2019) 929-941.

[46] H. Ansari, F. De Zan, A. Parizzi, Study of systematic bias in measuring surface deformation with SAR interferometry.

[47] C. Harris, D. V. Mühll, K. Isaksen, W. Haeberli, J. L. Sollid, L. King, P. Holmlund, F. Dramis, M. Guglielmin, D. Palacios, Warming permafrost in European mountains, Global and Planetary Change 39 (3-4) (2003) 215225.

[48] G. Liu, L. Zhao, R. Li, T. Wu, K. Jiao, C. Ping, Permafrost warming in the context of step-wise climate change in the Tien Shan mountains, China, Permafrost and Periglacial Processes 28 (1) (2017) 130-139.

[49] Shiklomanov N.I.,Streletskiy D. A., Little J. D., Nelson F. E, Isotropic thaw subsidence in undisturbed permafrost landscapes, Geophysical Research Letters, 40(24), (2013) 6356-6361.

[50] Streletskiy D. A., Shiklomanov N. I., Little J. D., Nelson F. E., Brown J., Nyland K. E., Klene A. E, Thaw subsidence in undisturbed tundra landscapes, Barrow, Alaska, 1962?2015, Permafrost and Periglacial Processes, 28(3), (2017) 566-572. 